\title{
A Lagrangian description on the troposphere-to-stratosphere transport changes associated with the stratospheric water drop around the year 2000
}

\author{
Fumio Hasebe $^{1,2}$ and Taisuke Noguchi ${ }^{2, \mathrm{a}}$ \\ ${ }^{1}$ Faculty of Environmental Earth Science, Hokkaido University, Sapporo, Japan \\ ${ }^{2}$ Graduate School of Environmental Science, Hokkaido University, Sapporo, Japan \\ a now at: Human Asset Management and Corporate Affairs Unit, FUJITSU FSAS INC., Kawasaki, Japan \\ Correspondence to: Fumio Hasebe (f-hasebe@ees.hokudai.ac.jp)
}

Received: 10 August 2015 - Published in Atmos. Chem. Phys. Discuss.: 19 October 2015

Revised: 18 December 2015 - Accepted: 16 February 2016 - Published: 4 April 2016

\begin{abstract}
The sudden decrease in stratospheric water vapor at around the year 2000 to 2001 is relatively well accepted in spite of the difficulty to quantify the long-term variations. This stepwise change is studied by examining the entry value of water to the stratosphere $\left(\left[\mathrm{H}_{2} \mathrm{O}\right]_{\mathrm{e}}\right)$ and some Lagrangian diagnostics of dehydration taking place in the tropical tropopause layer (TTL). The analysis is made using the backward kinematic trajectories initialized every $\sim 10$ days from January 1997 to December 2002 at $400 \mathrm{~K}$ potential temperature surface in the tropics. The $\left[\mathrm{H}_{2} \mathrm{O}\right]_{\mathrm{e}}$ is estimated by the ensemble mean value of the water saturation mixing ratio (SMR) at the Lagrangian cold point (LCP) where SMR becomes minimum $\left(\mathrm{SMR}_{\min }\right)$ in the TTL before reaching the $400 \mathrm{~K}$ surface. The drop in $\left[\mathrm{H}_{2} \mathrm{O}\right]_{\mathrm{e}}$ is identified to have occurred in September 2000. The horizontal projection of September trajectories, tightly trapped by anticyclonic circulation around the Tibetan high, shows eastward expansion since the year 2000. Associated changes are measured by three-dimensional bins, each having the dimension of $10^{\circ}$ longitude by $10^{\circ}$ latitude within the TTL. The probability distribution of LCPs shows an appreciable change exhibiting a composite pattern of two components: (i) the dipole structure consisting of the decrease over the Bay of Bengal and Malay Peninsula and the increase over the northern subtropical western Pacific and (ii) the patterns of the decrease over the equatorial western Pacific and the increase over the central Pacific that are almost symmetric with respect to the Equator. The $\mathrm{SMR}_{\min }$ shows a general decrease in the tropics with some enhancement in the central Pacific. The expecta-
\end{abstract}

tion values, defined by the multiple of the probability of LCP events and the ensemble mean values of $\mathrm{SMR}_{\min }$, are calculated on each bin for both periods prior and posterior to the drop. These values are the spatial projection of $\left[\mathrm{H}_{2} \mathrm{O}\right]_{\mathrm{e}}$ on an individual bin. The results indicate that the drop is brought about by the decrease in water transport borne by the air parcels that have experienced the LCP over the Bay of Bengal and the western tropical Pacific. The former is related to the eastward expansion of the anticyclonic circulation around the weakened Tibetan high, while the latter would be linked to the eastward expansion of western tropical warm water to the central Pacific. This oceanic surface forcing may be responsible also for the modulation of dehydration efficiency in the successive northern winter. The drop in September 2000 and the sustained low values thereafter of $\left[\mathrm{H}_{2} \mathrm{O}\right]_{e}$ are thus interpreted as being driven by the changes in thermal forcing from the continental and oceanic bottom boundaries.

\section{Introduction}

Stratospheric water vapor (SWV) observed by balloon-borne hygrometers exhibited a gradual increase in the 1980s and 1990s (Oltmans and Hofmann, 1995; Oltmans et al., 2000), followed by a stepwise drop at around the year 2000 (Scherer et al., 2008; Fujiwara et al., 2010). Since SWV has a positive radiative forcing as a greenhouse gas (Shindell, 2001), its possible increase during the two decades could have caused enhanced surface warming by about $30 \%$ as compared to 
that without taking this increase into account, while the subsequent drop could have slowed down the surface warming by about $25 \%$ from about 0.14 to $0.10^{\circ} \mathrm{C}$ per decade (Solomon et al., 2010). The cause and mechanism of this stepwise change have been extensively discussed (e.g., Randel et al., 2006; Rosenlof and Reid, 2008; Bönisch et al., 2011; Fueglistaler, 2012; Fueglistaler et al., 2014; Dessler et al., 2014). While constructing a reliable long-term SWV record is still a challenge (Hegglin et al., 2014), the understanding of a possible stepwise change in SWV is required in assessing possible modulation of the Brewer-Dobson circulation under global warming.

The variation in SWV is driven dynamically by the troposphere-to-stratosphere transport of water and chemically by the oxidation of methane. The dynamical control is mostly associated with the efficiency of dehydration functioning on the air mass advected in the tropical tropopause layer (TTL) (Holton and Gettelman, 2001; Hatsushika and Yamazaki, 2003). The Lagrangian description of the transport processes in the tropical troposphere to the stratosphere using trajectory calculations proved to be quite effective not only in the reproduction of SWV variations but also in the characterization of the dehydration processes in the TTL (e.g., Bonazzola and Haynes, 2004; Fueglistaler et al., 2004, 2005; Dessler et al., 2014) even though the quantitative estimation of the water amount entering the stratosphere requires detailed consideration dealing with aerosols and ice particles (ice nucleation and sublimation processes, supersaturation, and deposition and precipitation of ice particles) as well as the minute description of meteorological conditions (subgrid-scale variabilities, intrusion of deep convection into advected air parcels, and irreversible mixing due to breaking waves along with the ambiguity in the analysis field).

Here, we discuss the cause of the stepwise drop in SWV by making the analysis of the entry mixing ratio of water to the stratosphere $\left(\left[\mathrm{H}_{2} \mathrm{O}\right]_{\mathrm{e}}\right)$ with the aid of some Lagrangian diagnostics of TTL dehydration such as the preferred advection pathways in the TTL, the location in which water saturation mixing ratio (SMR) takes minimum along each trajectory (Lagrangian cold point, LCP) together with the minimum value $\left(\mathrm{SMR}_{\min }\right)$ before entering the stratosphere (Sect. 3). The backward kinematic trajectories initialized at $400 \mathrm{~K}$ potential temperature surface in the tropics, similar to those of Fueglistaler et al. (2005), are used. The calculations cover the period from January 1997 to December 2002. The statistical features of the LCP and $\mathrm{SMR}_{\min }$ are analyzed for the 90-day trajectories in which the air parcels experienced LCP in the TTL (Sect. 2). The analysis is focused on the examination of the entry value of water to the stratosphere, meaning that any contribution from the recirculation within the stratosphere (ST) and the sideways entry of water into the ST without taking the LCP in the TTL are intentionally left out of the scope. Detailed examinations on the driving mechanism itself are left for future studies. However, such a restriction will serve to focus our investigation on some specific processes that may have led to the SWV drop in Lagrangian framework. This approach has an advantage over Eulerian description because the drop in SWV does not necessarily mean TTL cooling conveniently described in Eulerian framework. For example, it might simply reflect the change in the proportion of air parcels that have passed the coldest region in the TTL. Conversely, any extreme cooling does not necessarily result in enhanced dehydration as long as the air parcels do not experience LCP event in that region. We will try to describe a hypothetical story on the cause of the stepwise drop in SWV through the discussion of the results in Sect. 4. Conclusions are given in Sect. 5.

\section{Method of analysis}

\subsection{Trajectory calculations}

The method of estimating $\left[\mathrm{H}_{2} \mathrm{O}\right]_{\mathrm{e}}$ in the present study is similar to that of Fueglistaler et al. (2005). $\left[\mathrm{H}_{2} \mathrm{O}\right]_{\mathrm{e}}$ at time $t$ is estimated as the ensemble mean value of $\mathrm{SMR}_{\min }$ along 90-day backward kinematic trajectories initialized at $t$. The backward trajectory calculations are started from uniformly distributed grid points (every $5.0^{\circ}$ longitude by $1.5^{\circ}$ latitude) within $30^{\circ} \mathrm{N}$ and $\mathrm{S}$ from the Equator at $400 \mathrm{~K}$ potential temperature surface. The initializations are made on the 5 th, 15 th, and 25th of every month during the period from January 1997 to December 2002, relying on the European Centre For Medium-Range Weather Forecasts ERA-Interim data set (Dee et al., 2011). The number of initialization points is 2952 for a single calculation, resulting in 8856 for the estimation of monthly values. This number compares well with that of the reduced set of trajectories in the study on the sensitivity of number of trajectories by Bonazzola and Haynes (2004) and turned out to be enough to derive statistically significant results as can be seen later in Sect. 3. All meteorological variables given on 60 model levels have been interpolated to those on 91 pressure levels, keeping the horizontal resolution of $0.75^{\circ}$ by $0.75^{\circ}$ longitude-latitude grid points prior to calculations. The time step has been set to $30 \mathrm{~min}$, similar to the 36 min used by Bonazzola and Haynes (2004), by applying spatiotemporal interpolations to the $6 \mathrm{~h}$ interval ERA-Interim data set. As for the limitation and caution of this method, see, for example, the pioneering studies by Fueglistaler et al. (2004) and Bonazzola and Haynes (2004).

\subsection{Selection of trajectories relevant to TTL dehydration}

The meridional projections of the backward trajectories extracted from those initialized on 15 January 1999 are shown in Fig. 1. The top and bottom diagrams are the same except that pressure (top) and potential temperature (bottom) are taken as the ordinate. The asterisks in red indicate the location of the LCP, while those in green are the termination point of trajectory calculations (90 days before initialization 

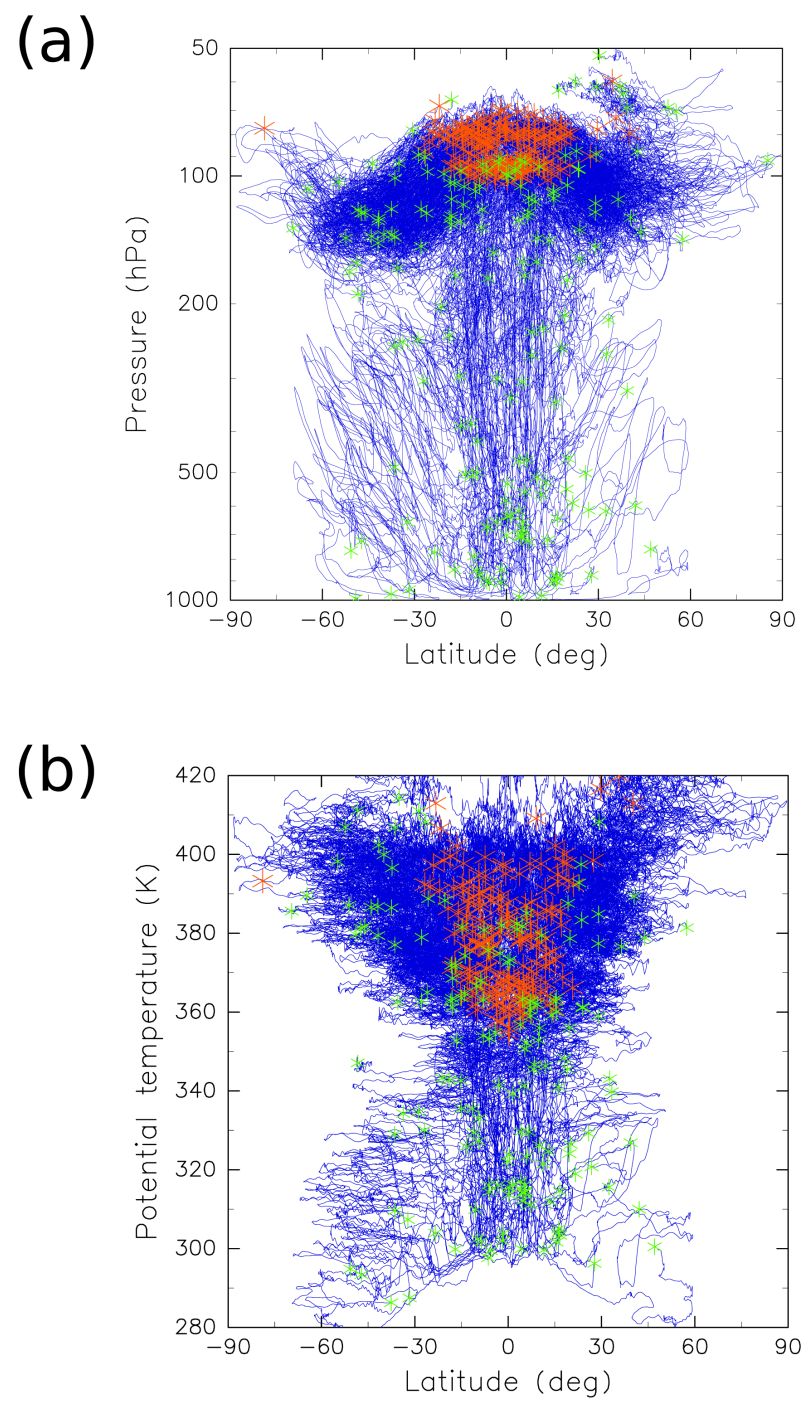

Figure 1. The meridional projections in (a) pressure and (b) isentropic coordinates of 90-day kinematic backward trajectories initialized at $400 \mathrm{~K}$ potential temperature surface at 15 January 1999. Initial positions are set at $5.0^{\circ}$ longitude by $1.5^{\circ}$ latitude grid points covering the tropical zone within $30^{\circ} \mathrm{N}$ and $\mathrm{S}$ from the Equator. Those shown here are the subsets in which the initial positions are trimmed to $20.0^{\circ}$ by $6.0^{\circ}$ grid points for visual clarity. The red asterisks are the Lagrangian cold points, while the green asterisks are the termination points of trajectory calculations. The calculations stop if the backward extension of the trajectories hits the surface of the Earth in less than 90 days before initialization.

at the longest). If the backward extension of the trajectories hits the surface of the Earth, the calculations are terminated at that point, and those portions of the trajectories immediately before the surface collision are used for the analysis. The migration of air parcels depicted in the trajectories is roughly categorized into three major branches: quasi-isentropic advection in the TTL and the lower stratosphere (LS), vertical displacement in the troposphere due to diabatic motion re- solvable in grid-scale velocity field, and quasi-isentropic migration in the troposphere. We can see that many air parcels are traced back to the troposphere, representing the tropical troposphere-to-stratosphere transport (TST), while some portions of the trajectories remain in the LS and/or reach the tropical $400 \mathrm{~K}$ surface by taking the sideways without making excursions in the TTL. All non-TST trajectories are removed from the following analysis to focus our discussion on the modulation of $\left[\mathrm{H}_{2} \mathrm{O}\right]_{\mathrm{e}}$. For the sake of clarity, the TST particles in the present study are defined as a subset of those particles traceable down to $340 \mathrm{~K}$ that have recorded LCP in the TTL. For the application of this LCP condition to our trajectories, we introduce the Lagrangian definition of the TTL to ensure internal consistency of the analysis.

The motion of air parcels ascending in the tropical troposphere is characterized by rapid convective uplift that accompanies latitudinal migration associated with the seasonal displacement of the Intertropical Convergence Zone. Up in the TTL, on the other hand, the diabatic ascent is associated with the dynamically driven relaxational radiative heating. The seasonal migration with respect to latitude is much smaller than that in the troposphere because the dynamical field generated by the thermal forcing at the bottom boundary retains relatively high symmetry with respect to the Equator. By translating these features into the characteristics of trajectories, we derive a definition of the TTL in a Lagrangian fashion.

The top panel of Fig. 2 illustrates the vertical distribution of the proportion of trajectories categorized on a daily basis as "fast" ascending air parcels. The required rate for the fast ascent is empirically set to more than $0.2 \mathrm{~K}$ in potential temperature within 1 time step $(30 \mathrm{~min})$ - that is, the condition for $\theta \mathrm{K}$ isentrope is met if the air parcel crosses $\theta \mathrm{K}$ surface from below $\theta-0.1 \mathrm{~K}$ to above $\theta+0.1 \mathrm{~K}$ in $30 \mathrm{~min}$. We can see that the proportion of the fast diabatic ascent thus defined becomes maximum at around $340 \mathrm{~K}$ in the troposphere and minimum at around $355 \mathrm{~K}$. The proportion of such "fast" air parcels reduces above the level of main outflow and rapidly decreases to near zero toward the level of zero net radiative heating in the TTL. Above this level, the air parcels are diabatically lifted up by radiative heating and further pumped up by dissipating planetary waves in the midlatitude stratosphere (Holton et al., 1995). The alternation of the primary forcing that drives diabatic ascent is also seen from the bottom panel of Fig. 2, which shows the seasonal migration of the latitudinal position of the trajectories traceable to down below $340 \mathrm{~K}$ averaged for (blue) January, (green) April, (yellow) July, and (red) October. The altitude of the kink at around $355 \mathrm{~K}$ suggests that the influence of tropical convective motion almost ceases at this level and the diabatic forcing gradually shifts to radiative heating in the TTL and above.

The diagnostic features depicted in Fig. 2 agree that the bottom of the TTL would be most properly defined at $355 \mathrm{~K}$ potential temperature level for our study. In the following 


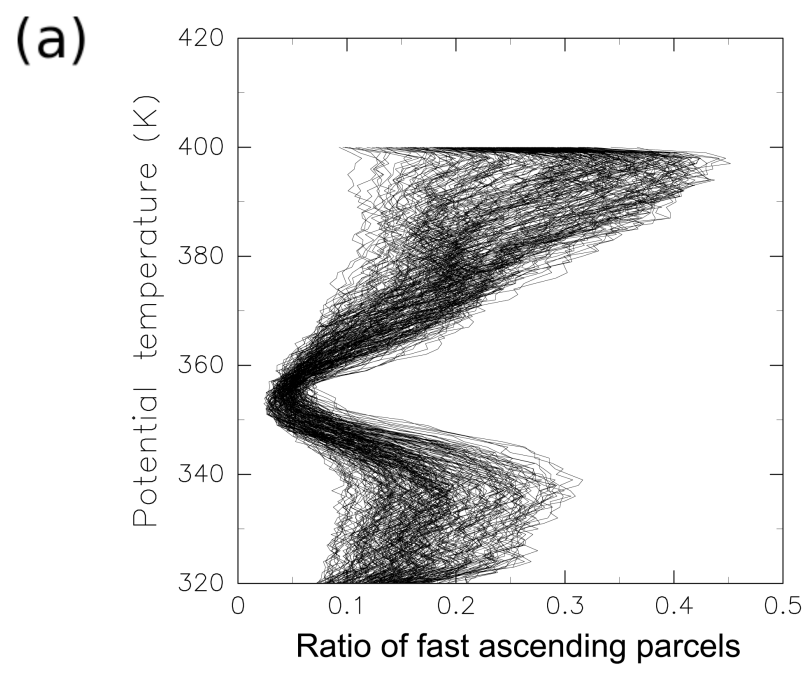

(b)

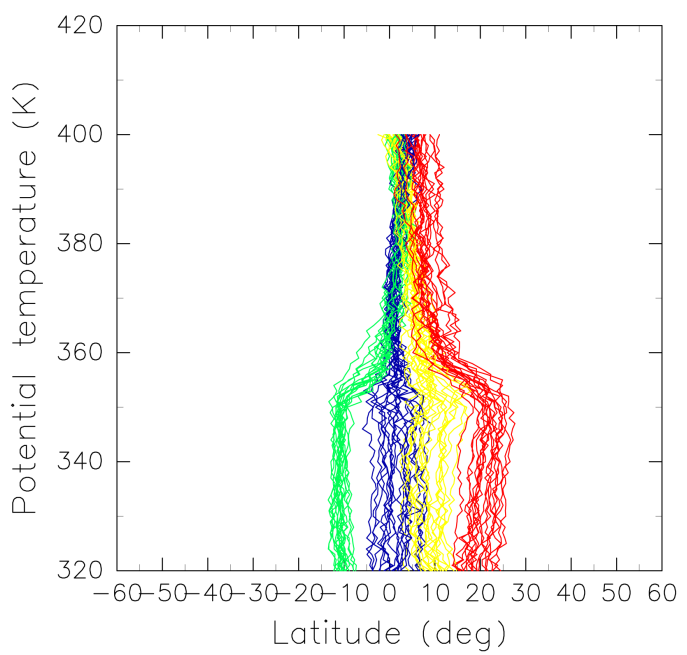

Figure 2. The vertical profiles of (a) proportion of the "fast" ascending air parcels and (b) averaged ascending track diagnosed by 90-day kinematic back trajectories that extends from $400 \mathrm{~K}$ to the lower troposphere below $340 \mathrm{~K}$ potential temperature surface. The upward motion on $\theta \mathrm{K}$ isentrope is categorized as "fast" if the air parcel crosses $\theta \mathrm{K}$ surface from below $\theta-0.1 \mathrm{~K}$ to above $\theta+0.1 \mathrm{~K}$ in $30 \mathrm{~min}$. Each line in (a) shows the daily proportion of trajectories at each isentropic level that correspond to "fast" ascending air parcels. The ascending tracks in (b) are color-coded on a monthly basis (January in blue, April in green, July in yellow, and October in red) to visualize the seasonal migration of the ascending latitude in the tropics.

analysis, we make use of TST trajectories defined by the air parcels that have ascended from the lower troposphere below $340 \mathrm{~K}$ isentrope experiencing the LCP in the TTL, which is defined by the layer between the isentropic levels 355 and $400 \mathrm{~K}$ within $30^{\circ} \mathrm{N}$ and $\mathrm{S}$ from the Equator. (a)

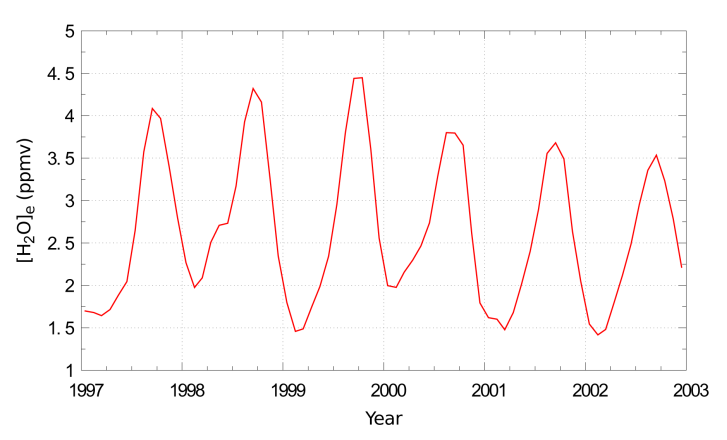

(b)

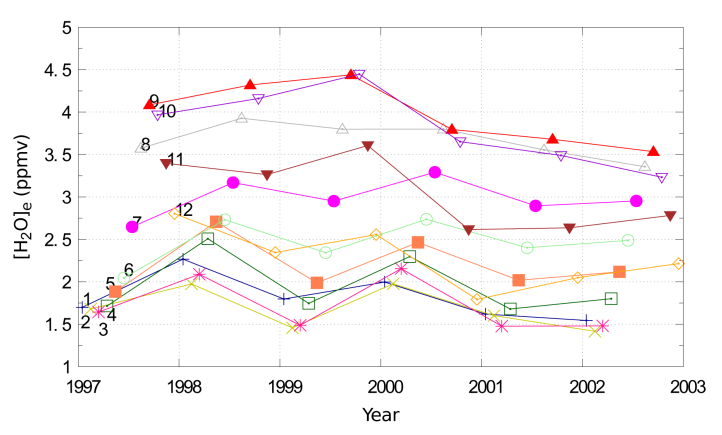

Figure 3. The time series of the ensemble mean values of $\left[\mathrm{H}_{2} \mathrm{O}\right]_{e}$ (ppmv) estimated from the TST trajectories initialized on the corresponding month. The data points are connected by sequential month in (a), while they are linked by each calendar month to visualize interannual variations on a monthly basis in (b). The labels 1 through 12 designate January through December of each year. The significance interval at $1 \%$ level is roughly the size of each symbol in the lower panel.

\section{Results}

\subsection{The drop in $\left[\mathrm{H}_{2} \mathrm{O}\right]_{\mathrm{e}}$}

The calculations are made on a monthly basis using the three initialization days (5th, 15th, and 25 th of each month) at a time. The following description refers to a specific month, with the suffix for time omitted. Let us start by assuming that the minimum saturation mixing ratio along $i$ th TST trajectory $\left(i=1, \cdots, N_{\mathrm{TST}}\right)$ is denoted by $\mathrm{SMR}_{\min i}$. The entry value of water to the stratosphere $\left[\mathrm{H}_{2} \mathrm{O}\right]_{\mathrm{e}}$ is defined as the ensemble mean value of $\mathrm{SMR}_{\min }$ as in Fueglistaler et al. (2005):

$\left[\mathrm{H}_{2} \mathrm{O}\right]_{\mathrm{e}}=\frac{1}{N_{\mathrm{TST}}} \sum_{i}^{N_{\mathrm{TST}}} \mathrm{SMR}_{\min i}$.

The evolution of the entry value of water to the stratosphere as modeled in $\left[\mathrm{H}_{2} \mathrm{O}\right]_{\mathrm{e}}$ time series is shown in Fig. 3. The top panel is the sequential change in the monthly ensemble mean value of $\left[\mathrm{H}_{2} \mathrm{O}\right]_{\mathrm{e}}$ estimated from the TST air parcels during the period between January 1997 and December 2002. We can see the decrease in the seasonal maxima in boreal summer in 2000. The seasonal minima in boreal winter, on the other hand, show larger values in January-February 2000 
(a)

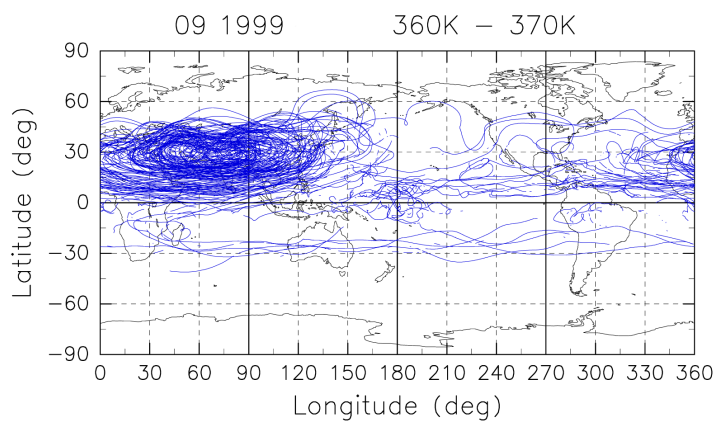

(b)

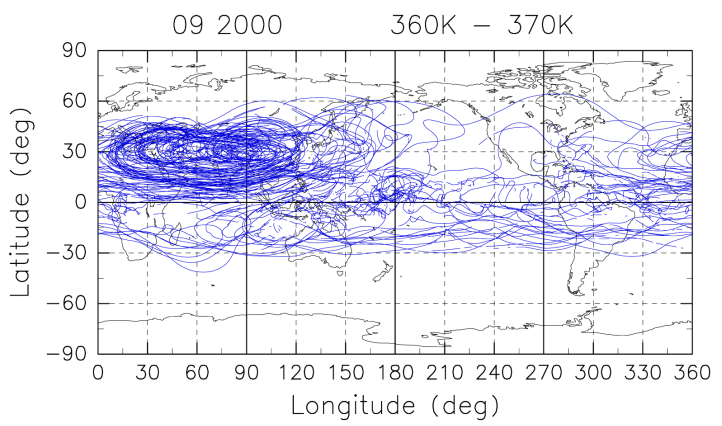

Figure 4. Horizontal projection of the backward trajectories extracted within the potential temperature levels between 360 and $370 \mathrm{~K}$. The initialization is made at $400 \mathrm{~K}$ potential temperature surface between $30^{\circ} \mathrm{N}$ and $\mathrm{S}$ from the Equator (Sect. 2) in (a) September 1999 and (b) September 2000. The illustration is limited to the subset of trajectories as in Fig. 1 for visual clarity.

as compared to those in 1999,2001 , and 2002, and thus the drop in $\left[\mathrm{H}_{2} \mathrm{O}\right]_{e}$ is not quite obvious. As the 6-year time series is not long enough to define climatology and anomalies from it, we simply view the interannual variations on the basis of each calendar month. The bottom panel of Fig. 3 is the same as the top except that the data points are connected by each calendar month. When viewed in this way, the drop in the year 2000 of about 1 ppmv shows up in the time change in September (marked as 9), October (10), November (11), and December (12). A similar drop continues to January (1) and the successive months in 2001. As there is little difference between those values of August 1999 and 2000 as seen in Fig. 3b, we may well conclude that the drop in $\left[\mathrm{H}_{2} \mathrm{O}\right]_{\mathrm{e}}$ occurred in September 2000. Considering the time period required for the air parcels to make excursion in the TTL, we may interpret that the change in the characteristics of dehydration has been initiated in the boreal summer of 2000. The maxima of $\left[\mathrm{H}_{2} \mathrm{O}\right]_{e}$ in January through June 1998 are related to the strong El Niño as is discussed later in Sect. 4.

\subsection{Horizontal projection of the TST trajectories}

As the first step of examining the change in the characteristics of TTL dehydration initiated in northern summer of 2000, Fig. 4 illustrates the horizontal projection of TST trajectories within the layer between the isentropes 360 and
$370 \mathrm{~K}$ extracted from those initialized in September 1999 (top) and 2000 (bottom). In spite of the equatorially symmetric assignment of the initialization points at $400 \mathrm{~K}$ potential temperature surface, the trajectories in the TTL are highly asymmetric with respect to the Equator and clustered mostly in the northern subtropics. The dense population of the trajectories shows that the air parcels are largely trapped by the Tibetan high in the region between $30^{\circ} \mathrm{W}$ and $150^{\circ} \mathrm{E}$ and 0 and $45^{\circ} \mathrm{N}$. Comparison between the two, representing September trajectories prior and posterior to the drop, respectively, reveals that the circulation of air parcels around the Tibetan high is loosely tied to the center in the latter period, resulting in the expansion of the anticyclonic circulation branch mostly to the east accompanied by the spreading out of the trajectories farther to the Southern Hemisphere in the latter. This modal shift in the trajectories initialized in September occurs in the year 2000 and continues at least through 2001 and 2002 (not shown).

\subsection{Statistical distribution of the LCP}

The shift in the circulation pattern of air parcels is not enough to characterize the modification of dehydration efficiency in the TTL. To quantify the change in the LCP distribution associated with the modal shift seen in Fig. 4, the numbers of LCPs are counted for every $10^{\circ}$ longitude-latitude bin in the tropics. The probabilities of LCPs are estimated for each bin by dividing the LCP counts by the total number of TST trajectories.

Let assume that $i$ th TST trajectory $\left(i=1, \cdots, N_{\mathrm{TST}}\right)$ takes minimum saturation mixing ratio $\left(\mathrm{SMR}_{\min i}\right)$ at bin $j(j=$ $1, \cdots, M)-$ that is, the Lagrangian cold point (LCP) for $i$ th TST trajectory is found at bin $j$. If we denote the number of LCP events at bin $j$ as $N(\mathrm{LCP} \in j)$,

$N_{\mathrm{TST}}=\sum_{j}^{M} N(\mathrm{LCP} \in j)$.

Because some trajectories do not satisfy the TST condition in general, $N_{\mathrm{TST}} \leq N$, where $N$ is the total number of initialization points used for the calculation. The probability of LCP events at bin $j, P(\mathrm{LCP} \in j)$, is defined by

$P(\mathrm{LCP} \in j)=\frac{N(\mathrm{LCP} \in j)}{N_{\mathrm{TST}}}$,

so that the normalization condition $\sum_{j}^{M} P(\operatorname{LCP} \in j)=1$ holds.

The top two panels of Fig. 5 show the horizontal distributions of $P(\mathrm{LCP} \in j)$ thus defined for those trajectories initialized in September 1998 and 1999 (a, prior to the drop) and September 2000, 2001, and 2002 (b, posterior to the drop). Because $N_{\text {TST }}$ is different among individual Septembers, $N_{\text {TST }}$ for each month has been used as a weight in taking the averages. In other words, the calculations are made by combining the trajectories of 2 or 3 prior or posterior 

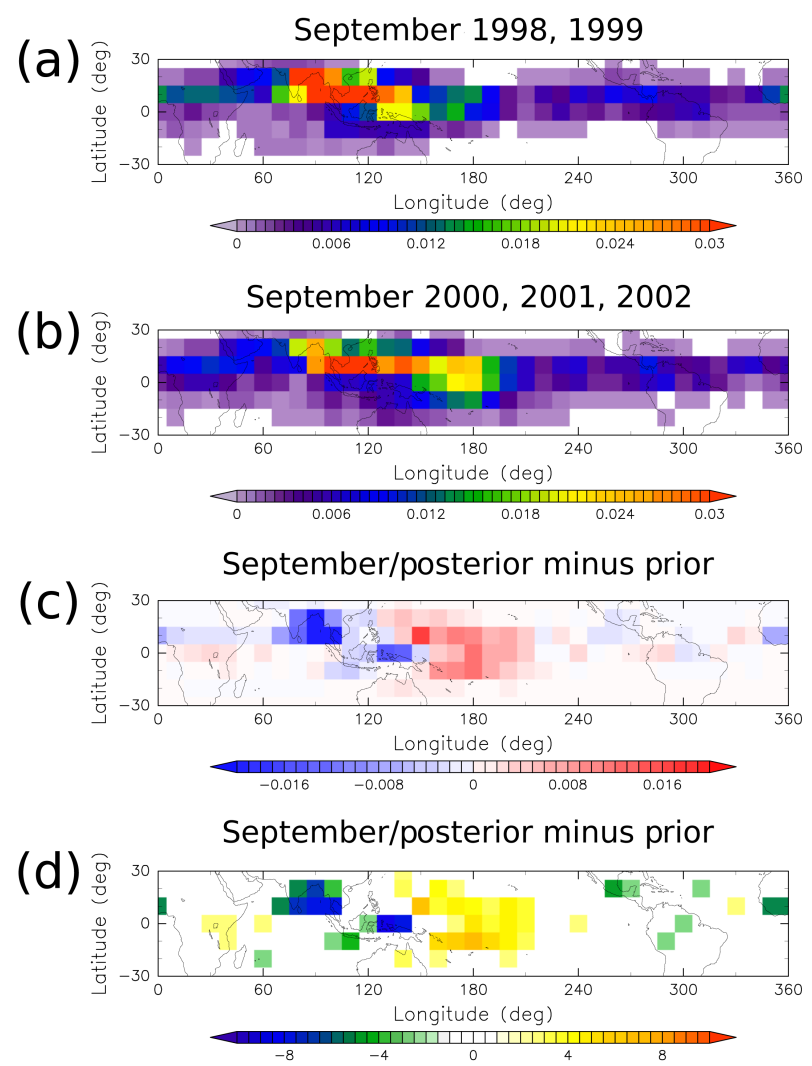

Figure 5. Horizontal distribution of LCP-event probability, $P(\mathrm{LCP} \in j)$, estimated from the TST trajectories initialized at $400 \mathrm{~K}$ in (a) September 1998 and 1999 (prior to the drop) and (b) September 2000, 2001, and 2002 (posterior to the drop). The probabilities are estimated in $10^{\circ}$ by $10^{\circ}$ longitude-latitude bin as the number of LCPs experienced by all TST air parcels inside the bin divided by the total number of TST parcels used for the calculation $\left(N(\mathrm{LCP} \in j) / N_{\mathrm{TST}}\right)$. Panels (c) and (d) are the difference of probabilities between the two (posterior minus prior to the drop) and the values of test statistic ( $T_{1}$ of Appendix A1), respectively. The colored bins indicate that the difference is statistically significant at the significance level of $1 \%$ or higher. Those bins shown in white indicate that no LCP event is found in (a) and (b), while the difference is not statistically significant in (c) and (d). See Appendix A for the details of statistical tests.

months together for the illustrations. To be more specific, the TST trajectories of September 1998 and 1999, selected from $N=2952 \times 3 \times 2$ trajectories, are combined together for the illustration of Fig. 5a, while those of September 2000, 2001, and 2002, selected from $N=2952 \times 3 \times 3$ trajectories, are used for Fig. 5b. The comparison between the two will shed light on the change in "the sampling effect" of Bonazzola and Haynes (2004). The spatial distribution is characterized by the maxima over the Bay of Bengal and Malay Peninsula accompanied by a ridge extending to South China Sea. It is interesting to note some similarity in the location to the spatial maxima of the first encounter of backward trajectories to $370 \mathrm{~K}$ isentrope for June to August 1999 shown by
Bonazzola and Haynes (2004). During the period posterior to the drop (Fig. 5b), the maxima show eastward expansion as far as $150^{\circ} \mathrm{E}$. There also appears to be some increase in the central Pacific covering both northern and southern subtropics crossing over the Equator. These two components appear clearer in the difference field shown in Fig. 5c. Those bins shown in blue (red) indicate the decrease (increase) in the LCP probabilities in the posterior period. The test statistic of the difference (see Appendix A1 for details) is shown in Fig. 5d, indicating the region in which the differences are statistically significant at the significance level of $1 \%$ or higher. It is interesting to note that, in addition to the dipole structure associated with the eastward expansion of the Tibetan anticyclone, the probabilities show a significant decrease over the Equator at around 130 to $140^{\circ} \mathrm{E}$ and an increase in a wider area almost symmetric with respect to the Equator $\left(160^{\circ} \mathrm{E}\right.$ to $160^{\circ} \mathrm{W}$ and $10^{\circ} \mathrm{S}$ to $10^{\circ} \mathrm{N}$ ). This structure will be discussed further in Sect. 4.

\subsection{Statistical change in the $\mathrm{SMR}_{\min }$}

The increase in LCP events in some bins does not necessarily mean enhanced dehydration over there. The next step is to examine the change in the $\mathrm{SMR}_{\min }$. This corresponds to focus on the change in "the temperature effect" of Bonazzola and Haynes (2004). Simultaneous with counting the LCP events, the values of SMR at the time of each LCP event $\left(\mathrm{SMR}_{\min }\right)$ have been summed up to calculate the average for each bin. The ensemble mean value of $\mathrm{SMR}_{\min }$ at bin $j$, $\operatorname{SMR}(\operatorname{LCP} \in j)$, is defined by

$\operatorname{SMR}(\operatorname{LCP} \in j)=\frac{1}{N(\mathrm{LCP} \in j)} \sum_{i}^{\mathrm{LCP} \in j} \mathrm{SMR}_{\min i}$,

where $\sum_{i}^{\mathrm{LCP} \in j}$ indicates the sum with respect to the subset of TST trajectories that take LCP at bin $j$.

Figure 6 is the same as Fig. 5 except that $\operatorname{SMR}(\operatorname{LCP} \in j)$ is illustrated rather than $P(\mathrm{LCP} \in j)$. We can see that the averages of $\mathrm{SMR}_{\min }$ in the tropics are roughly smaller in the eastern than in the western hemisphere, accompanying a broad minimum of about 3.5 to $3.7 \mathrm{ppmv}$ over the maritime continent during the period prior to the drop (Fig. 6a). The values show a general decrease in the tropics, with some enhanced drop in the central Pacific reaching less than $3.0 \mathrm{ppmv}$ in the period posterior to the drop (Fig. 6b). The gross features correspond well to the horizontal distribution of the LCP-averaged SMR of July/August 2001 estimated by Fueglistaler et al. (2004). The difference between the two periods (Fig. 6c), together with the statistical significance (Fig. 6d), confirms the pronounced decrease in $\mathrm{SMR}_{\min }$ in the central Pacific after 2000. On the other hand, the change in $\mathrm{SMR}_{\min }$ associated with the east-west dipole structure is not so remarkable in terms of the difference of $\mathrm{SMR}_{\min }$, although the tendency is the same. 


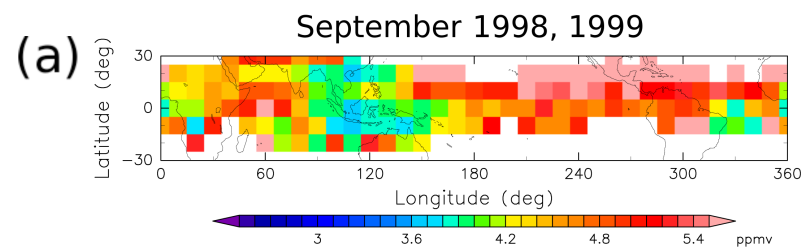

(b)

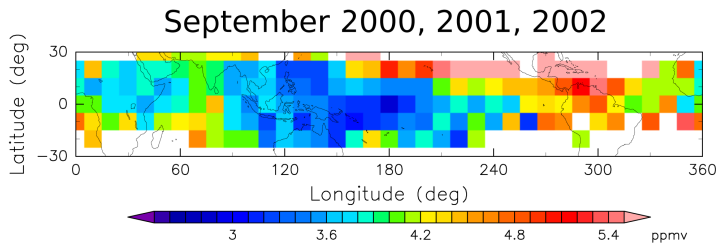

(C)

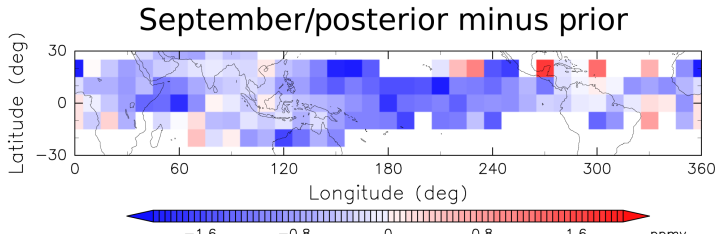

(d)

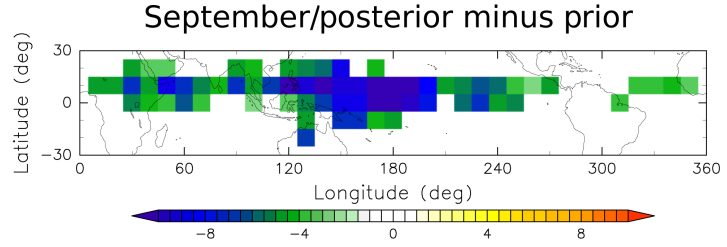

Figure 6. The same as Fig. 5 except that the ensemble mean values of $\mathrm{SMR}_{\min }$ are illustrated on a bin-by-bin basis ( $\mathrm{SMR}(\mathrm{LCP} \in j)$ ). The test statistic shown in (d) is $T_{2}$ of Appendix A2. See Appendix for the details.

\subsection{Statistical change in the expectation values}

While the differences of $\mathrm{SMR}_{\min }$ appear smaller over the Bay of Bengal and Malay Peninsula than over the central Pacific, the comparisons based only on the changes in $\operatorname{SMR}(\mathrm{LCP} \in j)$ could be misleading, because the values of $P(\mathrm{LCP} \in j)$ are much higher in the former than in the latter (Fig. 5). The expectation value for bin $j, E(\mathrm{LCP} \in j)$, is defined by the multiple of $P(\mathrm{LCP} \in j)$ and $\mathrm{SMR}(\mathrm{LCP} \in j)$ to quantify the contribution of each bin to $\left[\mathrm{H}_{2} \mathrm{O}\right]_{\mathrm{e}}$. The sum of $E(\mathrm{LCP} \in j)$ with respect to all bins reduces to

$$
\begin{aligned}
\sum_{j}^{M} E(\mathrm{LCP} \in j)= & \sum_{j}^{M} P(\mathrm{LCP} \in j) \times \operatorname{SMR}(\operatorname{LCP} \in j), \\
= & \sum_{j}^{M} \frac{N(\mathrm{LCP} \in j)}{N_{\mathrm{TST}}} \\
& \times \frac{1}{N(\mathrm{LCP} \in j)} \sum_{i}^{\mathrm{LCP} \in j} \mathrm{SMR}_{\min i}, \\
= & \frac{1}{N_{\mathrm{TST}}} \sum_{j}^{M} \sum_{i}^{\mathrm{LCP} \in j} \mathrm{SMR}_{\min i},
\end{aligned}
$$

(a)

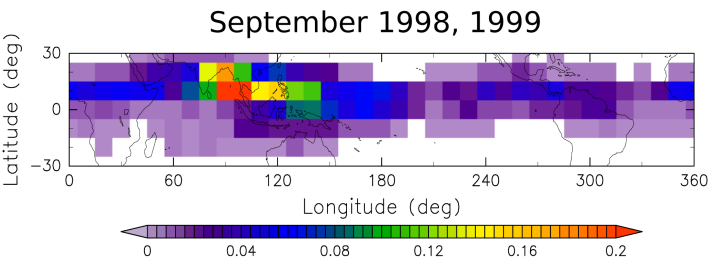

(b)

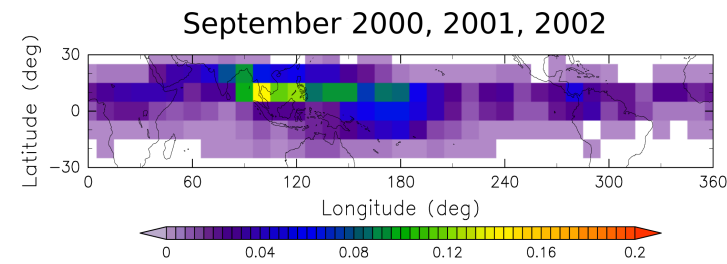

(c)

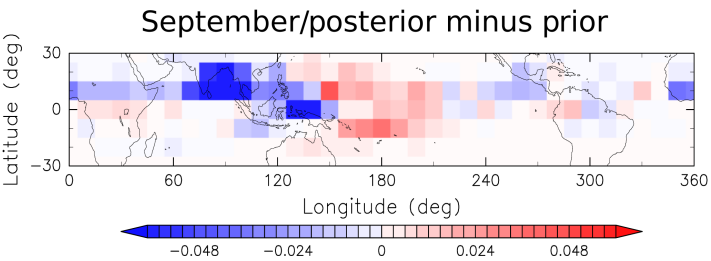

Figure 7. The same as the top three panels of Fig. 6 except that $E(\mathrm{LCP} \in j)$, the contribution of bin $j$ to $\left[\mathrm{H}_{2} \mathrm{O}\right]_{\mathrm{e}},(\mathrm{ppmv})$ is illustrated. See text for the definition of $E(\operatorname{LCP} \in j)$.

$$
=\frac{1}{N_{\mathrm{TST}}} \sum_{i}^{N_{\mathrm{TST}}} \mathrm{SMR}_{\min i} .
$$

This is the entry value of water to the stratosphere $\left[\mathrm{H}_{2} \mathrm{O}\right]_{\mathrm{e}}$ (Eq. 1), shown as a time series in Fig. 3. $\left[\mathrm{H}_{2} \mathrm{O}\right]_{\mathrm{e}}$ is thus decomposed of the sum of $E(\mathrm{LCP} \in j)$, which is interpreted as the contribution of bin $j$ to $\left[\mathrm{H}_{2} \mathrm{O}\right]_{\mathrm{e}}$. What is important here is that it is neither $P(\mathrm{LCP} \in j)$ nor $\operatorname{SMR}(\mathrm{LCP} \in j)$ but rather the product between the two, $E(\mathrm{LCP} \in j)$, that is directly responsible for composing the value $\left[\mathrm{H}_{2} \mathrm{O}\right]_{\mathrm{e}}$. By comparing the distribution of $E(\mathrm{LCP} \in j)$ between the two periods, prior and posterior to the drop, we can see how the drop in $\left[\mathrm{H}_{2} \mathrm{O}\right]_{e}$ is brought about by the change in water transport from an individual region.

Figure 7 shows the horizontal distribution of $E(\mathrm{LCP} \in j)$. This corresponds to the projection of $\left[\mathrm{H}_{2} \mathrm{O}\right]_{\mathrm{e}}$ onto each bin. We can see that the September values of $\left[\mathrm{H}_{2} \mathrm{O}\right]_{e}$ are mostly projected to the Bay of Bengal and Malay Peninsula before the drop (Fig. 7a). The contribution from this core area remains dominant during the posterior period (Fig. 7b). While the reduction of $\left[\mathrm{H}_{2} \mathrm{O}\right]_{\mathrm{e}}$ cannot be free from the general cooling (lowering of $\operatorname{SMR}(\mathrm{LCP} \in j)$ ) in posterior years over most of the tropics (Fig. 6), it is interesting to see the increase in $E(\mathrm{LCP} \in j)$ simultaneous with the decrease in $\operatorname{SMR}(\mathrm{LCP} \in j)$ over the central Pacific. This is because the increase in $P(\mathrm{LCP} \in j)$ more than compensates for the decrease in $\operatorname{SMR}(\mathrm{LCP} \in j)$ over there. In this sense, it is not appropriate to attribute the cooling over the western and the central Pacific to the drop in $\left[\mathrm{H}_{2} \mathrm{O}\right]_{\mathrm{e}}$. The similarity in the spatial distributions between $P(\mathrm{LCP} \in j)$ (Fig. 5) and 
(a)

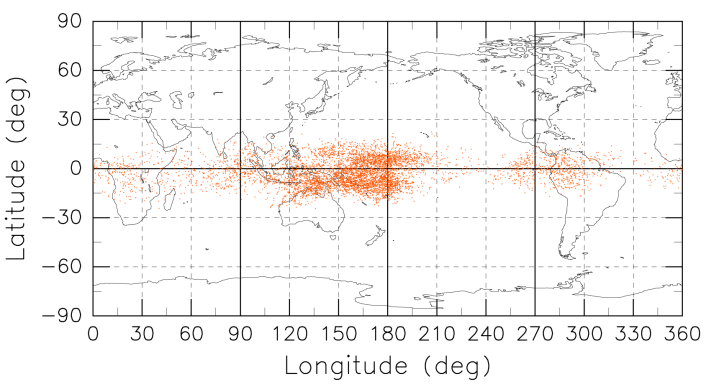

(b)

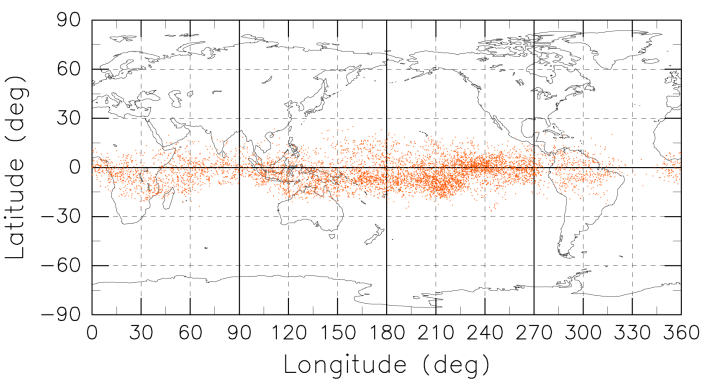

(c)

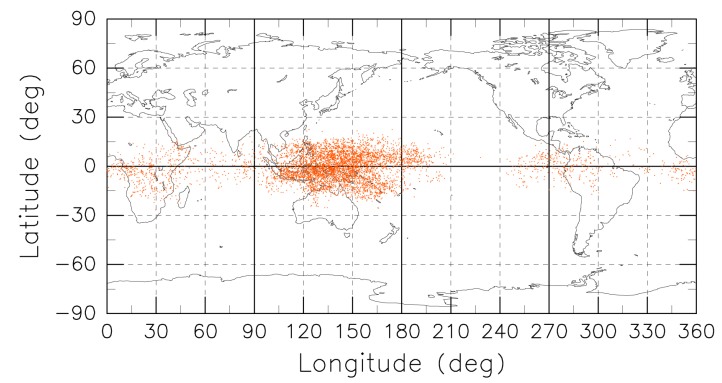

Figure 8. Horizontal distribution of LCP taken by all TST trajectories initialized at $400 \mathrm{~K}$ isentrope in February (a) 1997, (b) 1998, and (c) 1999.

$E(\mathrm{LCP} \in j)$ (Fig. 7) in the corresponding period, especially that between the location of maxima over the Bay of Bengal and Malay Peninsula (warm colors in panels a and b) together with the post-2000 decrease over there and the western tropical Pacific (dark blue in panel c), suggests that the relocation of LCPs (change in $P(\mathrm{LCP} \in j)$ ) is a leading factor that has caused the drop in $\left[\mathrm{H}_{2} \mathrm{O}\right]_{\mathrm{e}}$ in September 2000.

The resultant changes could be interpreted as the composite of two components: (i) the decrease over the Bay of Bengal and (ii) the patterns of the decrease over the equatorial western Pacific and the increase over the central Pacific that are almost symmetric with respect to the Equator and extending to the subtropical latitudes of both hemispheres. The former is supplemented by a slight decrease widespread along the $10^{\circ} \mathrm{N}$ zonal belt, with the exception around $150^{\circ} \mathrm{E}$ and the central Pacific. These features will be related to the eastward expansion of the anticyclonic circulation around the Tibetan high, while the latter is suggestive of some response to the thermal forcing from the equatorial ocean.

\section{Discussion}

\subsection{Maxima of $\left[\mathrm{H}_{2} \mathrm{O}\right]_{e}$ in 1998}

We have seen in Fig. 3 that the time series of $\left[\mathrm{H}_{2} \mathrm{O}\right]_{e}$ shows maxima in January through June 1998. We excluded these months from our analysis in Sect. 3 because of the influences of strong El Niño. The values of $\left[\mathrm{H}_{2} \mathrm{O}\right]_{e}$ in November and December 1997 are larger than those in 1998, which may also suggest the possible influence of El Niño in these months. Fueglistaler and Haynes (2005) demonstrated in their Fig. 2 that the trajectory model shows a large increase in lowerstratospheric water $\left(\left[\mathrm{H}_{2} \mathrm{O}\right]_{\mathrm{T} 400}\right.$, which takes non-TST trajectories into account in addition to $\left[\mathrm{H}_{2} \mathrm{O}\right]_{\mathrm{e}}$ ) associated with $\mathrm{El}$ Niño and that the increase is accompanied by the eastward shift of the high-density region of LCP. The reason why we regard these facts as little related to the drop in $\left[\mathrm{H}_{2} \mathrm{O}\right]_{\mathrm{e}}$ in 2000 is briefly discussed here.

For exploration of the reason of such anomalies, the horizontal distributions of LCP are shown for those initialized in February 1997, 1998, and 1999 in Fig. 8. The distributions in February 2000, 2001, and 2002 (not shown) are similar to those of 1997 and 1999. The LCPs in February are commonly distributed almost symmetric with respect to the Equator, but the longitudinal distribution is not uniform. High concentration in the western tropical Pacific in 1997 and 1999 (and also in 2000, 2001, and 2002) is suggestive of the strong influence of the warm sea surface temperature (SST) on the LCP distribution. The large scatter extending to the eastern tropical Pacific in 1998 is due to the migration of the large-scale convective system to the east associated with the strong El Niño. We have put this anomalous change out of the scope of the present study, because those anomalous values seem to have recovered to normal by the northern summer of 1998 (well before 2000) and there is no reasoning that this strong El Niño is coupled to the drop in $\left[\mathrm{H}_{2} \mathrm{O}\right]_{\mathrm{e}}$ in 2000. For the objective judgement of the influence of the El Niño, we employ the SST averaged in the region between 90 and $150^{\circ} \mathrm{W}$ longitude and $5^{\circ} \mathrm{S}$ and $5^{\circ} \mathrm{N}$ latitude (Niño 3 region; Trenberth, 1997). Those months exhibiting the SST anomalies (relative to the 1981-2010 climatology) greater than 1.5 times the standard deviation are excluded from the present analysis. Those excluded are the 12 months from June 1997 to May 1998.

\subsection{Perspective to the mechanism of the drop}

The entry value of water to the stratosphere, $\left[\mathrm{H}_{2} \mathrm{O}\right]_{\mathrm{e}}$, estimated by the ensemble mean values of $\mathrm{SMR}_{\min }$ along the TST trajectories, shows an appreciable decrease in September 2000 (Fig. 3), suggesting some modulation in the dehydration efficiency functioning on the air parcels advected in the TTL during the northern summer of 2000. The horizontal projection of September trajectories, characterized by anticyclonic circulation associated with the Tibetan high in 

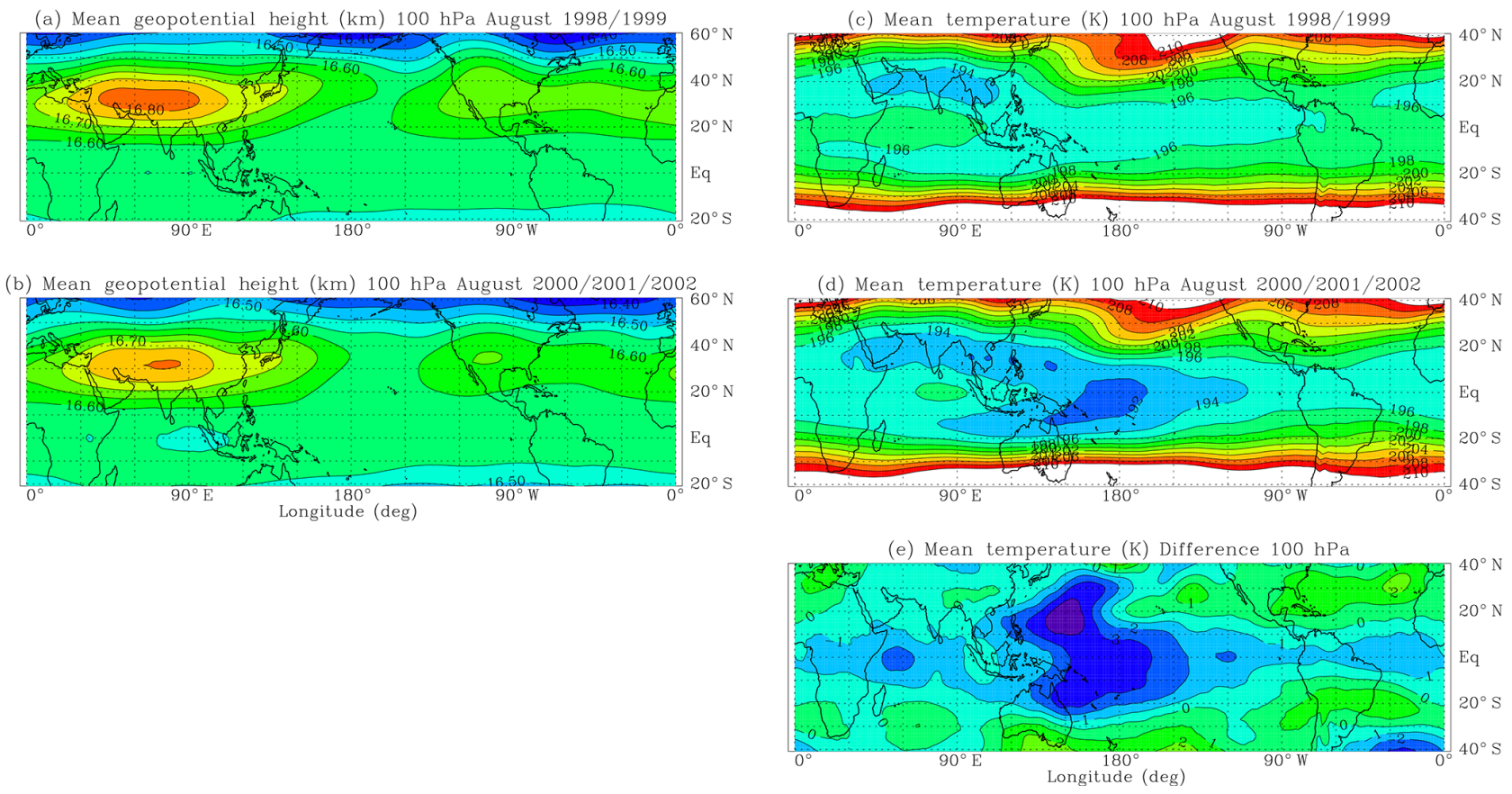

Figure 9. Longitude-latitude sections of (left) geopotential height $(\mathrm{km})$ and (right) temperature $(\mathrm{K})$ at $100 \mathrm{hPa}$ averaged in August 1998 and 1999 (a, c) and 2000, 2001, and 2002 (b, d) as well as the difference between the two (e) estimated from the ERA-Interim data set. Note the difference of latitudinal range between the left- and the right-hand figures.

the TTL, shows eastward expansion in the year 2000 accompanied by some bifurcation to the Southern Hemisphere (Fig. 4). This modal shift appears as decreases in the probability distribution of the LCP over the Bay of Bengal and the western tropical Pacific (Fig. 5). The SMR averaged on the occasion of LCP events $\left(\mathrm{SMR}_{\min }\right)$ shows a general decrease, with some enhancement in the central Pacific (Fig. 6). These results suggest two possible components contributing to the sudden drop in $\left[\mathrm{H}_{2} \mathrm{O}\right]_{e}$ in September 2000: the modulations of the Tibetan high and the TTL circulation driven by the thermal forcing from the equatorial ocean. The regional contribution to $\left[\mathrm{H}_{2} \mathrm{O}\right]_{\mathrm{e}}$, quantified by $E(\mathrm{LCP} \in j)$, shows a distinct decrease in two regions: one over the Bay of Bengal and the other over the Equator in the western tropical Pacific (Fig. 7c). The former will be related to the weakening of the Tibetan high, while the latter may imply the modulation of the Matsuno-Gill pattern (Matsuno, 1966; Gill, 1980), although these will not be independent of each other. The results indicate that the drop is brought about by a response of the TTL circulation to the modulated forcing both from the continental summer monsoon and the equatorial ocean. It is thus quite interesting to take a brief look at the changes in the TTL meteorological fields in Eulerian framework before concluding this study.

Figure 9 illustrates the longitude-latitude section of $100 \mathrm{hPa}$ geopotential height (left) and temperature (right) averaged in August 1998 and 1999 (top) and 2000, 2001, and 2002 (middle). These are the background Eulerian fields that have roughly brought about the Lagrangian features described by the top two panels of Figs. 5-7. We can see the Tibetan anticyclone in the height field of both periods (left), with the intensity weaker in the latter $(2000,2001$, and 2002) than in the former (1998 and 1999). This feature appears basically the same in individual monthly mean values of August, depending on the category either prior or posterior to the drop. The expansion of the trajectories after 2000 (Fig. 4), therefore, is the result of loosened grip of air parcels around the weakened Tibetan high in the latter years. These features remain the same in September of other years posterior to the drop (not shown). The temperature field (right-hand side) both prior and posterior to the drop appears as the typical pattern of the TTL response to the thermal forcing at the bottom boundary with additional heating to the subtropical Northern Hemisphere (Matsuno, 1966; Gill, 1980). The difference (Fig. 9e) indicates substantial cooling in the northern subtropics at around $150^{\circ} \mathrm{E}$ and the central Pacific. The latter corresponds to the findings of Rosenlof and Reid (2008), in which the tropical tropopause temperature in 171 to $200^{\circ} \mathrm{E}$ longitude band decreased in association with the SWV drop in 2000 .

The correspondence of the decrease in the equatorial $100 \mathrm{hPa}$ temperature to the increase in the underlying SST is explored in Fig. 10, which shows the longitude-time section of the equatorial SST averaged between $10^{\circ} \mathrm{N}$ and $\mathrm{S}$ of the Equator. We could see that the warm SST region in the western Pacific expands to the east in the year 2000, and the 
contour of $28^{\circ} \mathrm{C}$, the threshold of active convection (Gadgil et al., 1984), during the coldest month of the year crossed the date line in 2001. The possible connection of the water drop in 2000 to the modified SST distribution has been discussed by Rosenlof and Reid (2008). They found that the correlation coefficients between tropopause temperature and SST are quite small "if one correlates times prior to 2000, or after 2001" separately, but a large negative correlation coefficient of -0.44 appears if one correlates the entire time period, which, they say, is "exclusively a consequence of the decrease in tropical tropopause temperatures of $\sim 2{ }^{\circ} \mathrm{C}$ in $171-$ $200^{\circ}$ longitude band coincident with an increase in SSTs of $0.4^{\circ} \mathrm{C}$ in the $139-171^{\circ}$ tropical longitude band". The longitudinal difference between the warm SST core and the temperature minimum near the tropopause will be due to the eastward tilt of the cold region associated with a steady Kelvin wave response to underlying convective heating (Hatsushika and Yamazaki, 2003). Thus the notion of Rosenlof and Reid (2008) suggests that the SWV drop in 2000 is driven by some dynamical process that accompanies the generation of the Matsuno-Gill pattern. This is consistent with the idea that the modified SST distribution is one of the key processes that drove the water drop in the year 2000. The warm condition in the central Pacific continues at least until the end of 2005. The decrease of $100 \mathrm{hPa}$ temperature over the central Pacific is thus well correlated with this SST variation. The important point in our analysis is that the decrease in $\operatorname{SMR}(\operatorname{LCP} \in j)$, albeit widely distributed and remarkable in the tropics (Figs. 6 and 9), is not enough to explain the drop in $\left[\mathrm{H}_{2} \mathrm{O}\right]_{\mathrm{e}}$ if we recognize the dipole structure - that is, the paired increase and decrease - in $E(\mathrm{LCP} \in j)$ over the equatorial Pacific (Fig. 7). The modified pathway of TTL trajectories, resulting in the reduction of LCP probabilities over the Bay of Bengal and the western tropical Pacific (Fig. 5), is quite important.

The study by Young et al. (2012), discussing the changes in the Brewer-Dobson circulation during the period 1979 to 2005 by referring to the out-of-phase temperature relationship between the tropics and the extratropics, found no appreciable change around the year 2000. However, the zonally uniform component exhibiting the out-of-phase relationship between the tropics and the extratropics in the $100 \mathrm{hPa}$ temperature difference (Fig. 9) is suggestive of some stratospheric contribution to the drop in $\left[\mathrm{H}_{2} \mathrm{O}\right]_{\mathrm{e}}$ (Randel et al., 2006) through wave-driven pumping (Holton et al., 1995). The analysis of dynamical fields such as eddy heat flux and EP (Eliassen-Palm) flux by Fueglistaler (2012) finds a strengthening of the residual circulation qualitatively consistent with the drop in SWV in October 2000. Figure 11 shows in color the time-height section of monthly mean vertical wind velocity in the tropics. The seasonal enhancement in the upward motion during northern winter shows up in the lowermost stratosphere. The solid and dashed contours superposed on the vertical velocity field are the zonal wind components depicting the westerly and the easterly phase, re-

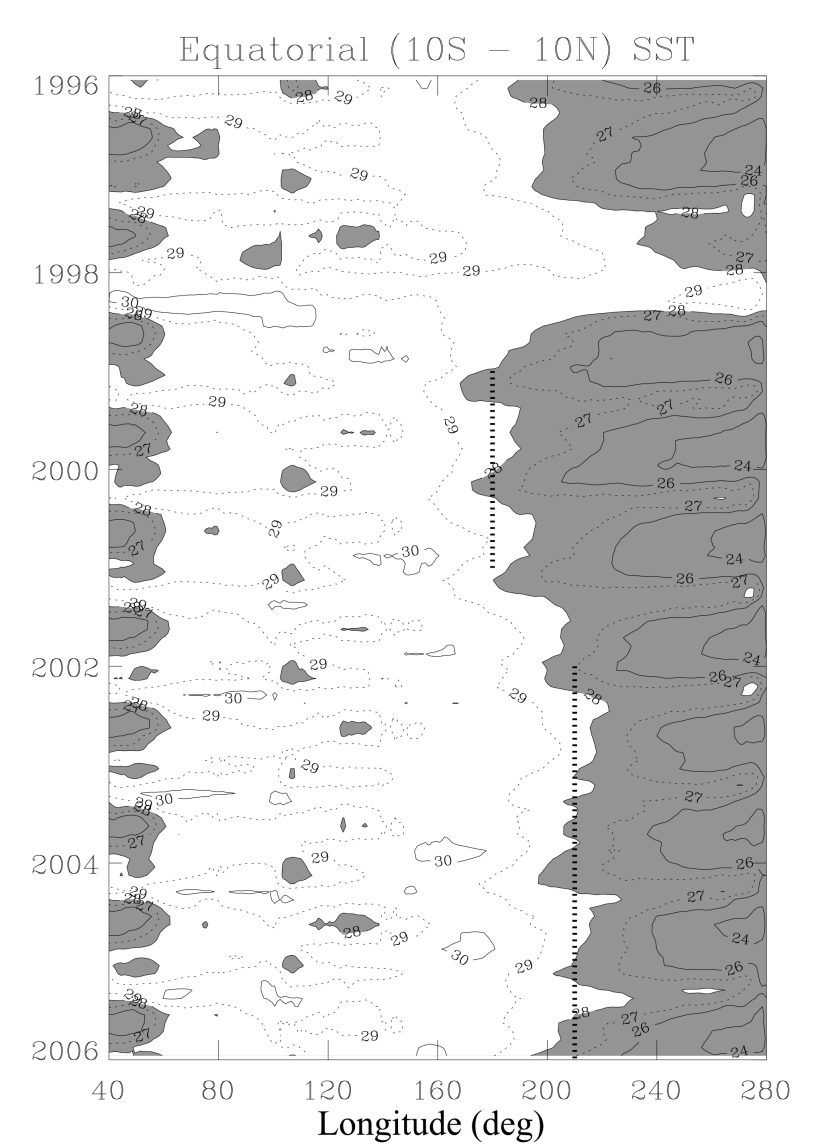

Figure 10. Longitude-time section of sea surface temperature (SST) averaged over the oceanic region of the latitude band between $10^{\circ} \mathrm{N}$ and $\mathrm{S}$ of the Equator during the period from January 1996 to December 2005. The region with the SST colder than $28^{\circ} \mathrm{C}$ is shaded. The dashed line spans from January 1999 to December 2000 along $180^{\circ} \mathrm{E}$ and from January 2002 to December 2005 along $210^{\circ} \mathrm{E}$. Data are from NOAA OI SST V2.

spectively, of the quasi-biennial oscillation (QBO). The stagnation of the downward propagation, specifically that of the easterly phase of the QBO, is noticed in late 1997 to early 1998 and late 2000 to early 2001 at around $40 \mathrm{hPa}$ level. This phase dependency of the stagnant propagation is brought about by the secondary circulation of the QBO, in which the upward (downward) motion accompanies the easterly (westerly) shear zone of the QBO (Plumb and Bell, 1982; Hasebe, 1994). What is interesting here is that the enhanced upward motion is found to be blocking the downward propagation of easterlies in September and October 2000. The limitation from our use of Eulerian vertical velocity, rather than transformed Eulerian mean (TEM) residual velocity, will be minimal as we focus our discussion on the tropics. The anomalies in the equatorial upwelling at $78 \mathrm{hPa}$ estimated by Rosenlof and Reid (2008) show similar results. Further analysis by Fueglistaler et al. (2014) emphasizes that the strengthening of the residual circulation does not last long but continues 


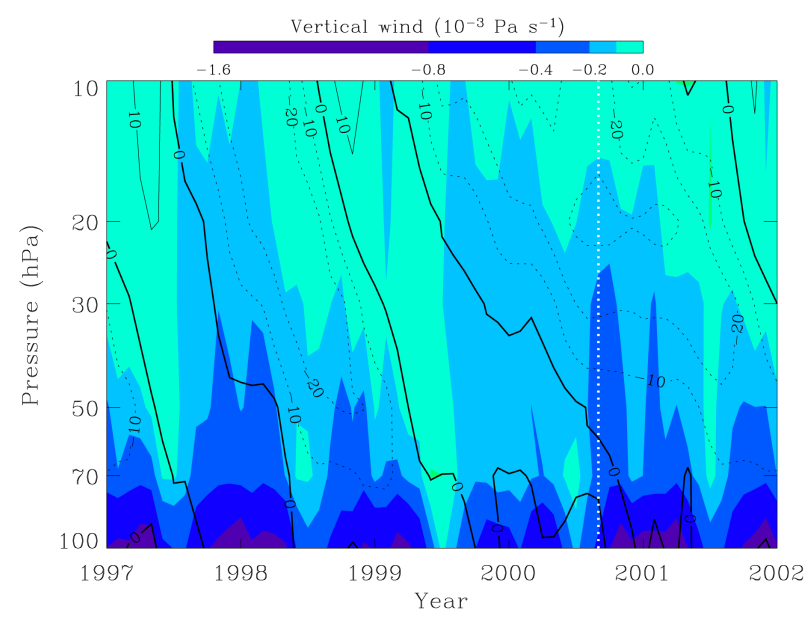

Figure 11. Time-height section of the zonally and latitudinally (within $15^{\circ} \mathrm{N}$ and $\mathrm{S}$ ) averaged monthly mean vertical (color, $10^{-3} \mathrm{~Pa} \mathrm{~s}^{-1}$ ) and zonal (contour, $\mathrm{m} \mathrm{s}^{-1}$ ) wind velocities from January 1997 to December 2001 calculated from the ERA-Interim data set. Solid (dashed) contours are westerlies (easterlies). Tick marks are January of the corresponding year, and the vertical dashed line in white marks September 2000.

for a few years around the year 2000. If we remember the time of excursion necessary for the air parcels to circulate the Tibetan high (Fig. 4), the stratospheric anomalies in October 2000 (Fueglistaler, 2012) appears later than the initiation of the drop in $\left[\mathrm{H}_{2} \mathrm{O}\right]_{\mathrm{e}}$. The difference of 1 month, albeit small, is large enough to be resolved in the analysis. Therefore, the enhanced upwelling discussed by Fueglistaler et al. (2014) might be the stratospheric response to the tropospheric forcing that modulated the dehydration efficiency in the preceding boreal summer of 2000 rather than the direct cause of the SWV drop. Further studies employing numerical simulations are definitely required. It is worth mentioning here that the enhancement of the Brewer-Dobson circulation may have also occurred in the northern hemispheric branch; the age of northern midlatitude stratospheric air diagnosed by the $\mathrm{CO}_{2}$ concentration appears shorter than usual in 2002 (Engel et al., 2009, Fig. 3), although the difference is not statistically significant.

\subsection{Perspective to the mechanism of a sustained low amount of $\left[\mathrm{H}_{2} \mathrm{O}\right]_{e}$}

We have seen some background meteorological fields from a Eulerian perspective to interpret the evidence presumably responsible for the drop in $\left[\mathrm{H}_{2} \mathrm{O}\right]_{\mathrm{e}}$ in September 2000 described in a Lagrangian framework. The problems not yet answered are what the specific event (if any) that has triggered the sequence of phenomena is and how it is generated. In addition, the sustained low values of $\left[\mathrm{H}_{2} \mathrm{O}\right]_{e}$ after September 2000 need some mechanism that lasts longer than the seasonal timescale, since the modulation of the Tibetan (a)

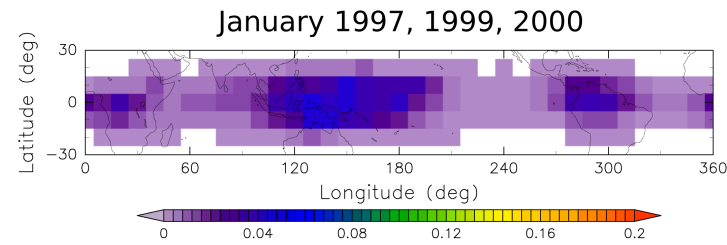

(b)

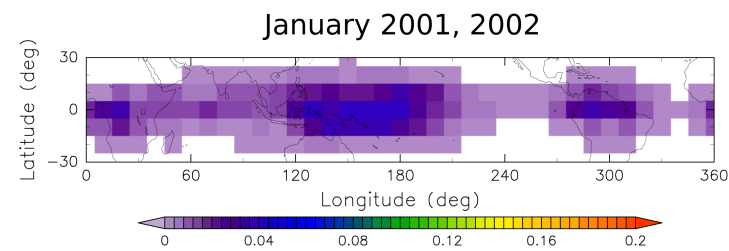

(C)

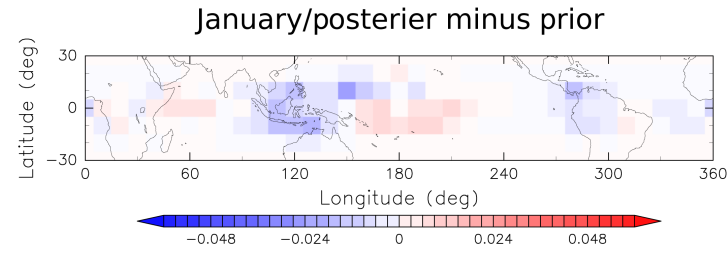

Figure 12. The same as Fig. 7 but for January. Those values in 1997, 1999, and 2000 are used for the calculations prior to the drop, while 2001 and 2002 are used for the posterior. Those in January 1998 are not used due to the influence of El Niño (see text).

high cannot explain the reduction continuing to the successive months in northern winter (Fig. 3).

Figure 12 is the same as Fig. 7 except that the January projection is illustrated. We can see that, in addition to the values generally lower than those in September, the larger values are found in the western tropical Pacific (Fig. 12a, b), indicating the January values of $\left[\mathrm{H}_{2} \mathrm{O}\right]_{\mathrm{e}}$ are controlled by those over the western Pacific. This is consistent with the picture that has been presented in numerical simulations (Hatsushika and Yamazaki, 2003). The difference between the two periods (Fig. 12c) shows decrease over Indonesia and increase over the central Pacific during the period posterior to the drop. The former is due to the combination of the decreases in both $P(\mathrm{LCP} \in j)$ and $\operatorname{SMR}(\operatorname{LCP} \in j)$, while the latter is brought about by the interplay between the increase in $P(\mathrm{LCP} \in j)$ and some decrease in $\operatorname{SMR}(\mathrm{LCP} \in j)$ (not shown). This situation is the same as what we see in September (Sect. 3.5). The similarity of this pattern - that is, the decrease in the equatorial western Pacific (over Indonesia) and the increase over the central Pacific - to that of the second component of September response suggests the existence of a common driver of the drop in $\left[\mathrm{H}_{2} \mathrm{O}\right]_{\mathrm{e}}$ irrespective of the season. This evidence suggests the idea that the drop in $\left[\mathrm{H}_{2} \mathrm{O}\right]_{\mathrm{e}}$ in northern winter has resulted from the response of the TTL circulation to the eastward expansion of the warm water to the central Pacific (Fig. 10) in such a way that the decrease in $E(\mathrm{LCP} \in j)$ in the western Pacific exceeds the increase in that in the central Pacific.

The correspondence to the change in the SST distribution, the time of occurrence, and the persistency of the phe- 
nomenon suggests that the drop and the subsequent low values of $\left[\mathrm{H}_{2} \mathrm{O}\right]_{\mathrm{e}}$ are brought about by the reduced water entry to the stratosphere mainly through the Bay of Bengal (in boreal summer) and the western tropical Pacific. The dipole pattern in $E(\mathrm{LCP} \in j)$ over the equatorial Pacific (Figs. 7 and 12) is suggestive of an eastward shift of the Matsuno-Gill pattern related to the eastward expansion of warm SST region to the central Pacific. Therefore our hypothetical story may read that the eastward expansion of warm SST region brings about the reduction of $\left[\mathrm{H}_{2} \mathrm{O}\right]_{\mathrm{e}}$ by TST air parcels passing through the western tropical Pacific during northern winter (Fig. 12), while the heating from the modulated SST mentioned above, competing against that over the continent, has led to the modal shift of trajectories during northern summer resulting in the reduced water transport over the Bay of Bengal and the western tropical Pacific (Fig. 7).

The above speculation might be completed given some proper explanation of the cause of the eastward expansion of the equatorial warm water to the central Pacific observed in 2000. In this context, it is interesting to see the possible occurrence of "El Niño Modoki" characterized by the warm SST event over the central Pacific (W. J. Randel, personal communication, 2015). The time series of normalized ENSO Modoki index of Ashok et al. (2007) changes from prolonged negative to positive towards 2001 . It is also interesting to note that the "La Niña-like condition", tied to the surface cooling of the equatorial eastern Pacific, is supposedly responsible for the recent hiatus, i.e., the pause of the global-mean surface air temperature rise (Kosaka and Xie, 2013; Watanabe et al., 2014). If this is proved to be true, we may have revealed another piece of the pathways that the internal variability in our climate system could exert on the surface cooling through SST-driven SWV fluctuations.

\section{Conclusions}

Backward kinematic trajectories, initialized at $400 \mathrm{~K}$ potential temperature surface in the tropics, have been employed to describe the stratospheric water drop observed at around 2000 to 2001 from a Lagrangian point of view. The entry value of water to the stratosphere, $\left[\mathrm{H}_{2} \mathrm{O}\right]_{e}$, shows appreciable decrease in the trajectories initialized in September 2000, suggesting the change in the TTL dehydration efficiency during the boreal summer of 2000. The following changes are found to be responsible for the drop in $\left[\mathrm{H}_{2} \mathrm{O}\right]_{\mathrm{e}}$. There is a reduction of water vapor transported by those air parcels that experienced LCP events in two regions: over the Bay of Bengal and the western tropical Pacific. The reductions are brought about by the decreases in both the LCP-event probability and the ensemble mean $\mathrm{SMR}_{\min }$ over both regions. The $\mathrm{LCP}$ reduction in the former region is related to the modified migration pathways of air parcels circulating the weakened Tibetan anticyclone, while that in the latter may be a response to eastward expansion of warm water to the central Pacific. This SST modulation seems to be also responsible for the decrease in $\left[\mathrm{H}_{2} \mathrm{O}\right]_{\mathrm{e}}$ in the successive northern winter. Some indication of stratospheric contribution through intensified pumping appears only intermittent and is better interpreted as a response to tropospheric forcing changes. 


\section{Appendix A: Statistical tests between prior and posterior to the drop}

\section{A1 The difference of $P(\mathrm{LCP} \in j)$}

Let the random variable, $X$, be the number of event occurrences in some number of trials, $n$. The binomial distribution can be used to calculate the probabilities for each of $n+1$ possible values of $X(X=0,1, \cdots, n)$ if the following conditions are met: (1) the probability of the event occurring does not change from trial to trial, and (2) the outcomes for each of the $n$ trials are mutually independent. These conditions are rarely met, but real situations can be close enough to this ideal that the binomial distribution provides sufficiently accurate representations. The probability that the number of occurrence $X$ is $x$ among $n$ trials, $\operatorname{Pr}(X=x)$, follows the binomial distribution

$\operatorname{Pr}(X=x)=\left(\begin{array}{c}n \\ x\end{array}\right) p^{x}(1-p)^{n-x}, \quad(x=0,1, \cdots, n)$,

where $p$ is the probability of occurrence of the event.

The statistical test for the difference in the population proportion of two binomial populations, $p_{1}-p_{2}$, could be made as follows. Let the sample size and the sample proportion of the two sets be $n_{1}$ and $n_{2}$ and $m_{1} / n_{1}$ and $m_{2} / n_{2}$, respectively. The test statistic $T_{1}$, defined by

$T_{1}=\frac{m_{1} / n_{1}-m_{2} / n_{2}}{\sqrt{p^{*}\left(1-p^{*}\right)\left(1 / n_{1}+1 / n_{2}\right)}}, \quad p^{*}=\frac{m_{1}+m_{2}}{n_{1}+n_{2}}$,

follows approximately the standard normal distribution. The statistical test for the difference between $P(\mathrm{LCP} \in j)$ in prior and posterior periods could be done by applying the twosided tests under the null hypothesis of $p_{1}-p_{2}=0$ at some significance level $\alpha$, where $p_{1}$ and $p_{2}$ are the population proportion of LCP taking place at bin $j$ in the posterior and prior to the drop, respectively. In our case, $n_{1}$ and $n_{2}$ and $m_{1}$ and $m_{2}$ are $N_{\mathrm{TST}}$ and $N(\mathrm{LCP} \in j)$, respectively, for posterior (suffix 1) and prior (suffix 2) periods.

\section{A2 The difference of $\operatorname{SMR}(\operatorname{LCP} \in j)$}

The statistical test to be applied is the comparison of the population means of two normal distributions, $\mu_{1}$ and $\mu_{2}$, with unknown population variances. This test is sometimes called Welch's $t$ test. The test statistic $T_{2}$, defined by

$$
T_{2}=\frac{\bar{x}_{1}-\bar{x}_{2}}{\sqrt{s_{1}^{2} / n_{1}+s_{2}^{2} / n_{2}}},
$$

follows the $t$ distribution of the degree of freedom $m$, where

$m=\frac{\left(s_{1}^{2} / n_{1}+s_{2}^{2} / n_{2}\right)^{2}}{s_{1}^{4} /\left(n_{1}^{2}\left(n_{1}-1\right)\right)+s_{2}^{4} /\left(n_{2}^{2}\left(n_{2}-1\right)\right)}$.

Here, $n_{1}$ and $n_{2}, \bar{x}_{1}$ and $\bar{x}_{2}$, and $s_{1}^{2}$ and $s_{2}^{2}$ are the sample size, the sample mean, and the unbiased sample variance, respectively, of the two sets. The statistical test for the difference between $\operatorname{SMR}(\mathrm{LCP} \in j)$ in prior and posterior periods could be done by applying the two-sided tests under the null hypothesis of $\mu_{1}-\mu_{2}=0$ at some significance level $\alpha$. In our case, $n_{1}$ and $n_{2}, \bar{x}_{1}$ and $\bar{x}_{2}$, and $s_{1}^{2}$ and $s_{2}^{2}$ are $N(\operatorname{LCP} \in j), \operatorname{SMR}(\operatorname{LCP} \in j)$, and the unbiased variance of $\mathrm{SMR}_{\min }$ at bin $j$, respectively, for posterior (suffix 1) and prior (suffix 2) periods. 
Acknowledgements. This work is based on the master of science thesis of T. Noguchi submitted to the Graduate School of Environmental Science, Hokkaido University, in February 2015. T. Noguchi is grateful to the members of the Graduate School of Environmental Science for the encouragement and discussions through the preparation of his thesis. The discussion with Koji Yamazaki of Hokkaido University is greatly appreciated. The results were presented in part at the CT3LS meeting held in July 2015. F. Hasebe is grateful for the comments from meeting participants, especially W. J. Randel of NCAR and K. H. Rosenlof of NOAA. The authors express their hearty gratitude to S. Fueglistaler (referee) and an anonymous reviewer for helpful and constructive comments. NOAA OI SST V2 data are provided by the NOAA/OAR/ESRL PSD, Boulder, Colorado, USA, from their Web site at http://www.esrl.noaa.gov/psd/. This work was supported by the Japan Society for the Promotion of Science, Grant-in-Aid for Scientific Research (S) 26220101.

Edited by: P. Jöckel

\section{References}

Ashok, K., Behera, S. K., Rao, S. A., Weng, H., and Yamagata, T.: El Niño modoki and its possible teleconnection, J. Geophys. Res., 112, c11007, doi:10.1029/2006JC003798, 2007.

Bonazzola, M. and Haynes, P. H.: A trajectory-based study of the tropical tropopause region, J. Geophys. Res., 109, D20112, doi:10.1029/2003JD004356, 2004.

Bönisch, H., Engel, A., Birner, Th., Hoor, P., Tarasick, D. W., and Ray, E. A.: On the structural changes in the Brewer-Dobson circulation after 2000, Atmos. Chem. Phys., 11, 3937-3948, doi:10.5194/acp-11-3937-2011, 2011.

Dee, D. P., Uppala, S. M., Simmons, A. J., Berrisford, P., Poli, P., Kobayashi, S., Andrae, U., Balmaseda, M. A., Balsamo, G., Bauer, P., Bechtold, P., Beljaars, A. C. M., van de Berg, L., Bidlot, J., Bormann, N., Delsol, C., Dragani, R., Fuentes, M., Geer, A. J., Haimberger, L., Healy, S. B., Hersbach, H., Hólm, E. V., Isaksen, L., Kållberg, P., Köhler, M., Matricardi, M., McNally, A. P., Monge-Sanz, B. M., Morcrette, J. J., Park, B. K., Peubey, C., de Rosnay, P., Tavolato, C., Thépaut, J. N., and Vitart, F.: The ERA-interim reanalysis: configuration and performance of the data assimilation system, Q. J. Roy. Meteor. Soc., 137, 553-597, 2011.

Dessler, A. E., Schoeberl, M. R., Wang, T., Davis, S. M., Rosenlof, K. H., and Vernier, J.-P.: Variations of stratospheric water vapor over the past three decades, J. Geophys. Res.Atmos., 119, 12588-12598, doi:10.1002/2014JD021712, 2014.

Engel, A., Möbius, T., Bönisch, H., Schmidt, U., Heinz, R., Levin, I., Atlas, E., Aoki, S., Nakazawa, T., Sugawara, S., Moore, F., Hurst, D., Elkins, J., Schauffler, S., Andrews, A., and Boering, K.: Age of stratospheric air unchanged within uncertainties over the past 30 Years, Nat. Geosci., 2, 28-31, 2009.

Fueglistaler, S.: Stepwise changes in stratospheric water vapor?, J. Geophys. Res., 117, D13302, doi:10.1029/2012JD017582, 2012.

Fueglistaler, S., and Haynes, P. H.: Control of interannual and longer-term variability of stratospheric water vapor, J. Geophys. Res., 110, D24108, doi:10.1029/2005JD006019, 2005.
Fueglistaler, S., Wernli, H., and Peter, T.: Tropical troposphereto-stratosphere transport inferred from trajectory calculations, J. Geophys. Res., 109, D03108, doi:10.1029/2003JD004069, 2004.

Fueglistaler, S., Bonazzola, M., Haynes, P. H., and Peter, T.: Stratospheric water vapor predicted from the Lagrangian temperature history of air entering the stratosphere in the tropics, J. Geophys. Res., 110, D08107, doi:10.1029/2004JD005516, 2005.

Fueglistaler, S., Abalos, M., Flannaghan, T. J., Lin, P., and Randel, W. J.: Variability and trends in dynamical forcing of tropical lower stratospheric temperatures, Atmos. Chem. Phys., 14, 13439-13453, doi:10.5194/acp-14-13439-2014, 2014.

Fujiwara, M., Vömel, H., Hasebe, F., Shiotani, M., Ogino, S.Y., Iwasaki, S., Nishi, N., Shibata, T., Shimizu, K., Nishimoto, E., Canossa, J. M. V., Selkirk, H. B., and Oltmans, S. J.: Seasonal to decadal variations of water vapor in the tropical lower stratosphere observed with balloon-borne cryogenic frostpoint hygrometers, J. Geophys. Res., 115, D18304, doi:10.1029/2010JD014179, 2010.

Gadgil, S., Joseph, P. V., and Joshi, N. V.: Ocean-atmosphere coupling over monsoon regions, Nature, 312, 141-143, 1984.

Gill, A. E.: Some simple solutions for heat-induced tropical circulation, Q. J. Roy. Meteor. Soc, 106, 447-462, 1980.

Hasebe, F.: Quasi-biennial oscillations of ozone and diabatic circulation in the equatorial stratosphere, J. Atmos. Sci., 51, 729-745, 1994.

Hatsushika, H. and Yamazaki, K.: Stratospheric drain over Indonesia and dehydration within the tropical tropopause layer diagnosed by air parcel trajectories, J. Geophys. Res., 108, 4610, doi:10.1029/2002JD002986, 2003.

Hegglin, M. I., Plummer, D. A., Shepherd, T. G., Scinocca, J. F., Anderson, J., Froidevaux, L., Funke, B., Hurst, D., Rozanov, A., Urban, J., von Clarmann, T., Walker, K. A., Wang, H. J., Tegtmeier, S., and Weigel, K.: Vertical structure of stratospheric water vapour trends derived from merged satellite data, Nat. Geosci., 7, 768-776, doi:10.1038/ngeo2236, 2014.

Holton, J. R. and Gettelman, A.: Horizontal transport and the dehydration of the stratosphere, Geophys. Res. Lett., 28, 2799-2802, 2001.

Holton, J. R., Haynes, P. H., McIntyre, M. E., Douglass, A. R., Rood, R. B., and Pfister, L.: Stratosphere-troposphere exchange, Rev. Geophys., 33, 403-439, 1995.

Kosaka, Y. and Xie, S.-P.: Recent global-warming hiatus tied to equatorial Pacific surface cooling, Nature, 501, 403-407, 2013.

Matsuno, T.: Quasi-geostrophic motions in the equatorial area, J. Meteorol. Soc. Jpn., 44, 25-43, 1966.

Oltmans, S. J. and Hofmann, D. J.: Increase in lower-stratospheric water vapour at a mid-latitude Northern Hemisphere site from 1981 to 1994, Nature, 374, 146-149, 1995.

Oltmans, S. J., Vömel, H., Hofmann, D. J., Rosenlof, K. H., and Kley, D.: The increase in stratospheric water vapor from balloonborne, frostpoint hygrometer measurements at Washington, D.C., and Boulder, Colorado, Geophys. Res. Lett., 27, 3453-3456, 2000.

Plumb, R. A. and Bell, R. C.: A model of the quasi-biennial oscillation on an equatorial beta-plane, Q. J. Roy. Meteor. Soc., 108, 335-352, 1982.

Randel, W. J., Wu, F., Vömel, H., Nedoluha, G. E., and Forster, P.: Decreases in stratospheric water vapor after 2001: links to changes in the tropical tropopause and the 
Brewer-Dobson circulation, J. Geophys. Res., 111, D12312, doi:10.1029/2005JD006744, 2006.

Rosenlof, K. H. and Reid, G. C.: Trends in the temperature and water vapor content of the tropical lower stratosphere: sea surface connection, J. Geophys. Res., 113, D06107, doi:10.1029/2007JD009109, 2008.

Scherer, M., Vömel, H., Fueglistaler, S., Oltmans, S. J., and Staehelin, J.: Trends and variability of midlatitude stratospheric water vapour deduced from the re-evaluated Boulder balloon series and HALOE, Atmos. Chem. Phys., 8, 1391-1402, doi:10.5194/acp8-1391-2008, 2008.

Shindell, D. T.: Climate and ozone response to increased stratospheric water vapor, Geophys. Res. Lett., 28, 1551-1554, 2001.
Solomon, S., Rosenlof, K. H., Portmann, R. W., Daniel, J. S., Davis, S. M., Sanford, T. J., and Plattner, G.-K.: Contributions of stratospheric water vapor to decadal changes in the rate of global warming, Science, 327, 1219-1223, 2010.

Trenberth, K. E.: The definition of El Niño, B. Am. Meteorol. Soc., 78, 2771-2777, 1997.

Watanabe, M., Shiogama, H., Tatebe, H., Hayashi, M., Ishii, M., and Kimoto, M.: Contribution of natural decadal variability to global warming acceleration and hiatus, Nature Clim. Change, 4, 893-897, doi:10.1038/Nclimate2355, 2014.

Young, P. J., Rosenlof, K. H., Solomon, S., Sherwood, S. C., $\mathrm{Fu}, \mathrm{Q}$., and Lamarque, J.-F.: Changes in stratospheric temperatures and their implications for changes in the BrewerDobson circulation, 1979-2005, J. Climate, 25, 1759-1772, doi:10.1175/2011JCLI4048.1, 2012. 